\title{
Recurrent abdominal pain and weight loss in an adolescent: Celiac artery compression syndrome
}

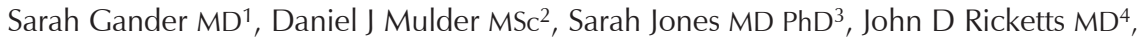 \\ Don A Soboleski $\mathrm{MD}^{4}$, Christopher J Justinich $\mathrm{MD}^{1,2}$
}

\begin{abstract}
S Gander, DJ Mulder, S Jones, JD Ricketts, DA Soboleski, CJ Justinich. Recurrent abdominal pain and weight loss in an adolescent: Celiac artery compression syndrome. Can J Gastroenterol 2010;24(2):91-93.

Celiac artery compression syndrome is a rare cause of abdominal pain and weight loss, likely caused by compression of the celiac artery or plexus by the median arcuate ligament. A case of celiac artery compression syndrome in a 17-year-old male patient with severe postprandial pain and weight loss is described. Imaging techniques such as computed tomography, angiography and Doppler ultrasound identified the abnormality, which was corrected by laparoscopic surgery.
\end{abstract}

Key Words: Abdominal pain; Celiac artery compression syndrome; Doppler ultrasound; Median arcuate ligament syndrome; Weight loss

$\mathrm{C}$ eliac artery compression syndrome (CACS), also known as median arcuate ligament syndrome, is a rare cause of postprandial pain and weight loss. CACS occurs when the median arcuate ligament and the origin of the celiac artery are in abnormally close proximity. This may be due to an abnormally inferior insertion of the diaphragm or an abnormally superior origin of the celiac artery (1). These anatomical anomalies may result in damage to the celiac nerve plexus or partial obstruction of blood flow through the celiac artery and its distributary vessels due to compression and tethering of the celiac artery during respiration.

In the pediatric patient, CACS has been associated with symptoms of weight loss, emesis and pain (2). CACS has been diagnosed in a variety of patients four years of age and older, the majority of whom are female (2). In some cases, the only clinical sign of CACS may be an abdominal bruit heard on systole (3). Imaging techniques including Doppler ultrasound (US), computed tomography (CT), magnetic resonance imaging (MRI) and selective catheter angiography can be used to identify the abnormality. Treatment involves surgical division of the median arcuate ligament and can now be performed using minimally invasive laparoscopic techniques.

\section{CASE PRESENTATION}

A case of a 17-year-old male patient who presented with a sixmonth history of severe, recurrent postprandial, periumbilical pain is described. The pain lasted 30 min to hours, and fear of eating led to a $16 \mathrm{~kg}$ weight loss. No nausea or vomiting was reported. Pain did not respond to over-the-counter analgesics. Typically, the patient had one to three formed stools per day. He denied extraintestinal manifestations of inflammatory bowel disease.

\author{
Des douleurs abdominales récurrentes et une \\ perte de poids chez un adolescent : Le \\ syndrome de compression de l'artère cœliaque
}

\begin{abstract}
Le syndrome de compression de l'artère cœliaque est une rare cause de douleurs abdominales et de perte de poids, probablement attribuables à la compression de l'artère cœliaque ou du plexus par l'arcade du psoas. Les auteurs décrivent un cas de syndrome de compression de l'artère cœliaque chez un adolescent de 17 ans manifestant de graves douleurs postprandiales et une perte de poids. Des techniques d'imagerie comme la tomodensitométrie, l'angiographie et l'échographie Doppler ont permis de repérer l'anomalie, qui a été corrigée par laparoscopie.
\end{abstract}

The patient's medical history included quiescent reactive airway disease and idiopathic hereditary sensory neuropathy. His medications included carbamazepine, gabapentin, inhaled budesonide and a beta-2 adrenergic agonist (terbutaline). Abdominal and perianal examinations were unremarkable, with no audible bruit, masses or hepatosplenomegaly. Initial laboratory investigations revealed normal values for complete and differential blood counts, erythrocyte sedimentation rate, serum albumin, liver enzymes and amylase. Laboratory investigations revealed an antigliadin immunoglobulin (Ig) A level of $25 \mathrm{kU} / \mathrm{L}$ (normal lower than $20 \mathrm{kU} / \mathrm{L}$ ), with normal tissue transglutaminase IgA. Upper gastrointestinal (GI) barium swallow with small bowel follow-through and abdominal US were normal. Endoscopy of the upper and lower GI tract was grossly normal and multiple biopsies revealed normal histology. The lack of evidence for celiac or inflammatory bowel disease led to additional imaging studies.

A focal stenosis at the origin of the celiac artery with poststenotic dilation was demonstrated by CT angiography (Figure 1). No other vascular abnormalities were seen. Radiographic selective catheter angiography revealed focal stenosis of the celiac artery, accentuated by expiration and improved on inspiration (Figure 2). Doppler US also demonstrated celiac artery stenosis with poststenotic dilation, and increased blood flow on expiration and improvement on inspiration (Figure 3).

Treatment of CACS in the present patient was surgical division of the median arcuate ligament by laparoscopic approach. Doppler US analysis of celiac artery flow was performed intraoperatively to ensure adequate decompression and was compared with postoperative superior mesenteric artery flow (Table 1). Pain resolved postoperatively and the patient regained $4.5 \mathrm{~kg}$

${ }^{1}$ Department of Pediatrics; ${ }^{2}$ Department of Anatomy and Cell Biology; ${ }^{3}$ Department of Surgery; ${ }^{4}$ Department of Diagnostic Radiology,

Queen's University, Kingston, Ontario

Correspondence: Dr Christopher J Justinich, Watkins 3, Room 4-316, 76 Stuart Street, Kingston, Ontario K7L 2V7.

Telephone 613-549-6666 ext 6375, fax 613-548-1368, e-mail justinic@kgh.kari.net

Received for publication April 16, 2009. Accepted May 8, 2009 


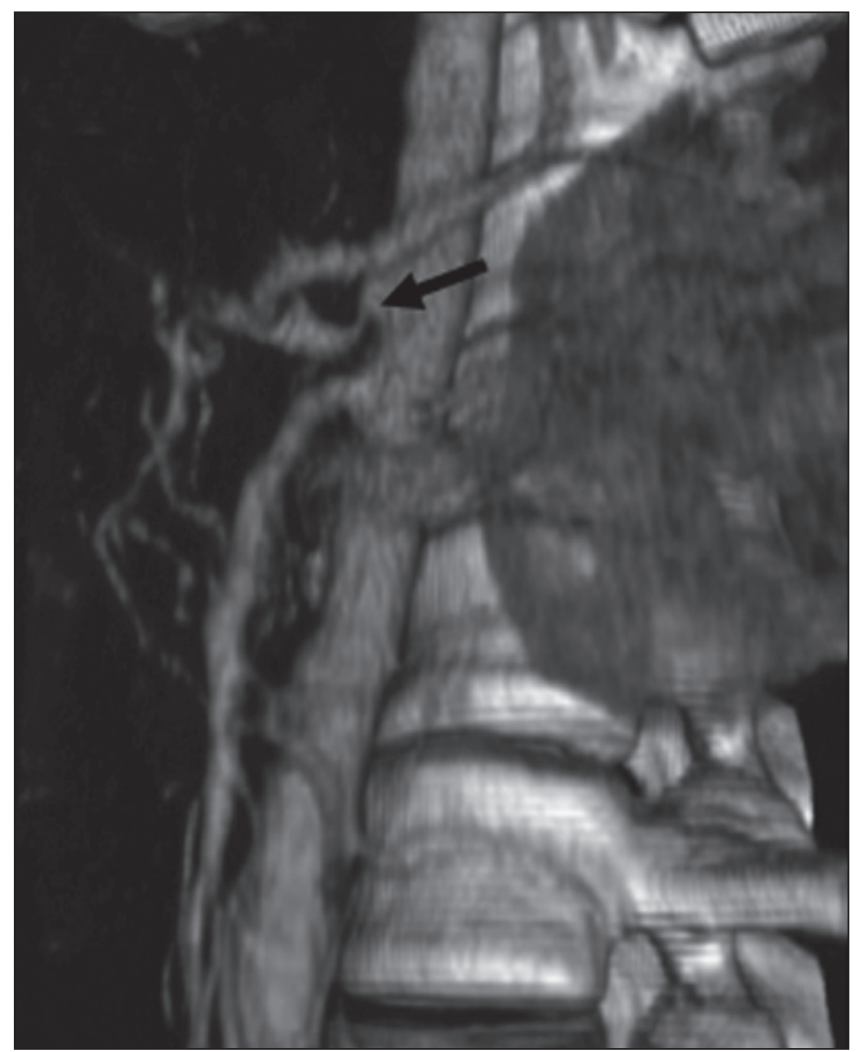

Figure 1) Three-dimensional reconstruction computed tomography angiography, revealing a stenosis (arrow) involving the proximal celiac artery compatible with celiac artery compression syndrome

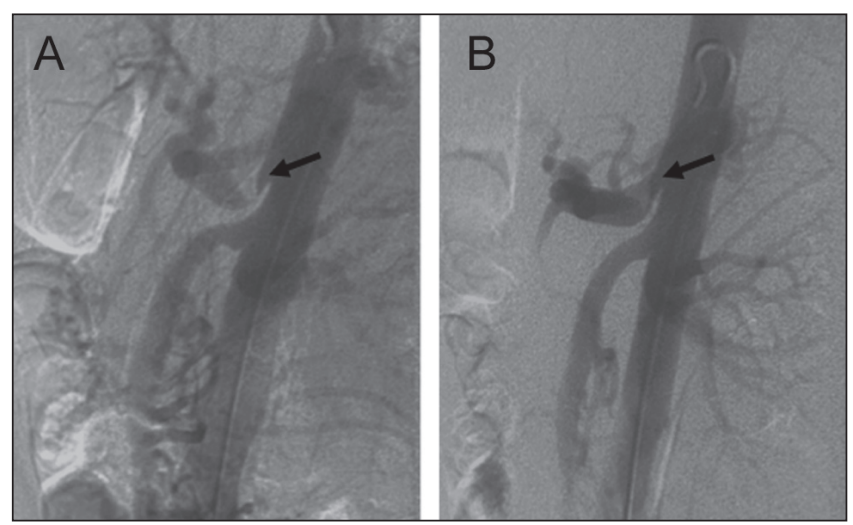

Figure 2) Direct catheter angiogram of the abdominal aorta at the origin of the celiac artery on expiratory (A) and inspiratory (B) phases of respiration, showing poststenotic dilation and location of the celiac artery stenosis (arrows)

in four months. Four months after the operation, follow-up Doppler US studies demonstrated increased turbulence at the origin of the celiac artery, likely due to previous surgical interventions. The rate of blood flow through the celiac artery was now more comparable with that of the superior mesenteric artery.

\section{DISCUSSION}

CACS results from an aberrant position of the origin of the celiac artery or abnormal location of the median arcuate
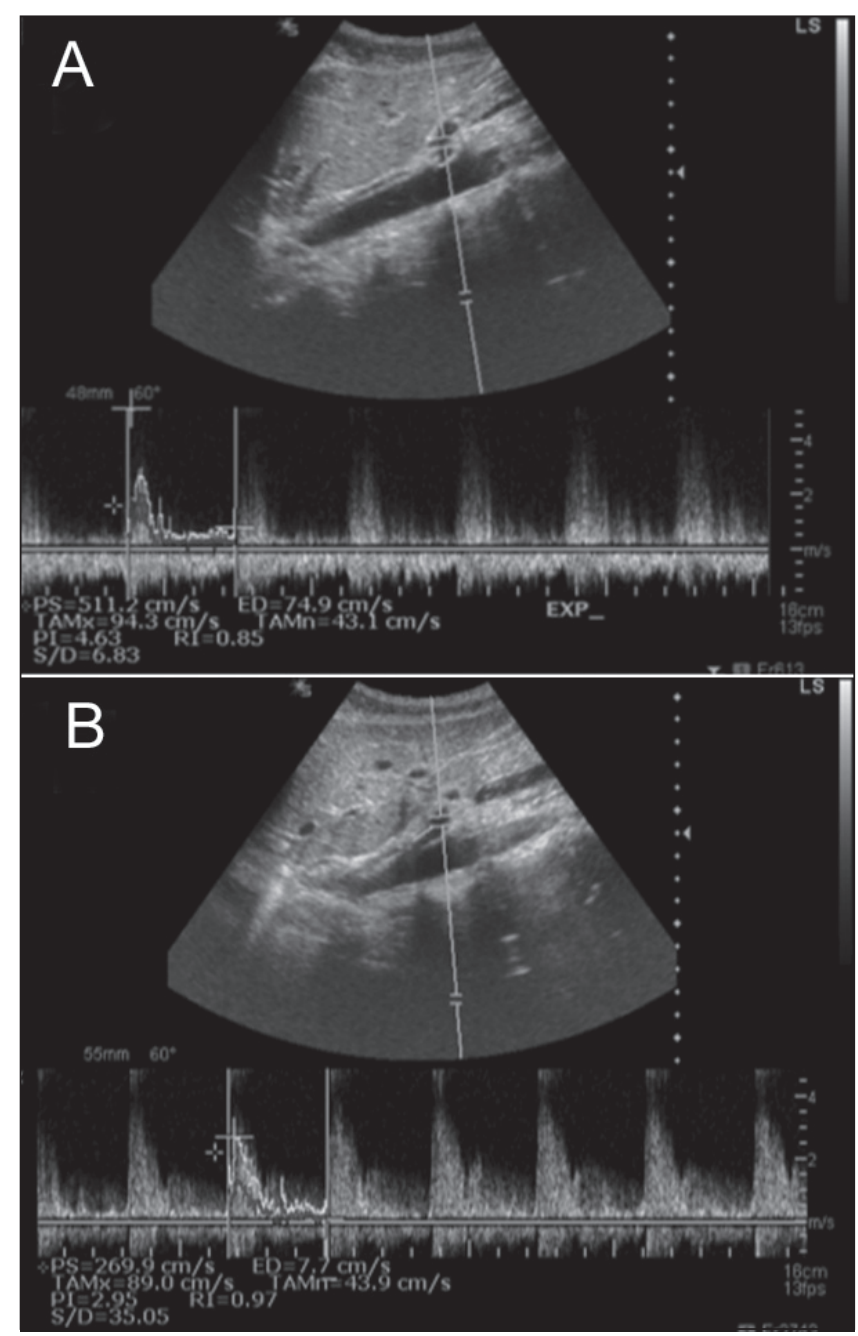

Figure 3) Doppler ultrasound of the celiac artery on expiration (A) and inspiration (B), demonstrating decreased flow on inspiration

\section{TABLE 1}

Peak systolic flow rates of celiac and superior mesenteric arteries on inspiration versus expiration, pre- and postoperatively

\begin{tabular}{lcc}
\hline & \multicolumn{2}{c}{ Peak systolic flow, cm/s } \\
\cline { 2 - 3 } & Inspiration & Expiration \\
\hline Celiac artery (preoperatively) & 269.9 & 511.2 \\
Celiac artery (postoperatively) & 305.4 & 339.3 \\
Superior mesenteric artery & 138.8 & 247.9 \\
\hline
\end{tabular}

ligament. Signs may include pain, anorexia, nausea, vomiting and an abdominal bruit (4). However, whether the anatomical abnormality visible on imaging studies is responsible for symptoms is controversial (5). Some have postulated that compression of the celiac artery by the median arcuate ligament may cause pain secondary to ischemia (6). Others suggest that involvement of the celiac splanchnic nerve plexus results in neuropathic pain (7), which is of interest in the present case due to the patient's underlying neuropathy.

CACS is rarely encountered in pediatric patients and symptoms may mimic other more common disorders. In one case (8), a 15-year-old male patient was diagnosed with Helicobacter pylori infection, which was eradicated. However, pain persisted 
despite the absence of abnormalities on gastroscopy. Digital subtraction angiography revealed CACS. CACS has also been reported in a 16-year-old patient after surgical correction of Scheuermann kyphosis causing widespread ischemic necrosis in the upper GI tract (9). In such cases, occlusion can lead to longterm damage of the celiac artery.

In the present case, CACS was visualized using CT angiography, Doppler US and selective catheter angiography. Doppler US provided a noninvasive technique to measure the rate of blood flow, enabling quantitative evaluation of celiac artery flow on inspiration and expiration, and comparison of flow rate before, during and after surgery. Additional diagnostic techniques that may be used to aid in the detection of CACS include MRI and angiography. Surgical release of the median arcuate ligament, performed by laparoscopic approach, is a safe alternative to laparotomy and was the therapy of choice in our case because it enabled better visualization of the abnormality (4). Other therapies have included transluminal dilation, stent placement and celiac artery bypass surgery (8).

The prognosis of CACS is unknown. The correlation between symptoms

\section{REFERENCES}

1. Dunbar JD, Molnar W, Beman FF, Marable SA. Compression of the celiac trunk and abdominal angina. Am J Roentgenol Radium Ther Nucl Med 1965;95:731-44.

2. Schweizer P, Berger S, Schweizer M, Schaefer J, Beck O. Arcuate ligament vascular compression syndrome in infants and children. J Pediatr Surg 2005;40:1616-22.

3. Alehan D, Dogan OF. Pediatric surgical image. A rare case: Celiac artery compression syndrome in an asymptomatic child. J Pediatr Surg 2004;39:645-7.

4. Carbonell AM, Kercher KW, Heniford BT, Matthews BD. Multimedia article. Laparoscopic management of median arcuate ligament syndrome. Surg Endosc 2005;19:729.

5. Balaban DH, Chen J, Lin Z, Tribble CG, McCallum RW. Median arcuate ligament syndrome: A possible cause of idiopathic gastroparesis. Am J Gastroenterol 1997;92:519-23. and radiographic findings is difficult to determine, and it is not known whether it is possible to demonstrate resolution by radiographic findings and symptoms. One study (3) reported that $76 \%$ of patients had long-term success following median arcuate ligament division surgery. Some adult patients have reported the return of CACSassociated pain after several years (10); thus, surgery may not be curative.

\section{CONCLUSION}

Although CACS is rare, it should be considered in pediatric patients with postprandial abdominal pain and weight loss. Doppler US is an effective screening test and detailed imaging techniques such as CT, MRI and direct catheter angiography can also be used for diagnosis. Laparoscopic repair by division of the median arcuate ligament is the treatment of choice.

ACKNOWLEDGEMENTS: The authors acknowledge support from Kingston General Hospital and the Queen's University Gastrointestinal Diseases Research Unit (Kingston, Ontario).

CONFLICTS OF INTEREST: The authors have no conflicts of interest to declare.

6. Cina CS, Safar H. Successful treatment of recurrent celiac axis compression syndrome. A case report. Panminerva Med 2002;44:69-72.

7. Loukas M, Pinyard J, Vaid S, Kinsella C, Tariq A, Tubbs RS. Clinical anatomy of celiac artery compression syndrome: A review. Clin Anat 2007;20:612-7.

8. Foertsch T, Koch A, Singer H, Lang W. Celiac trunk compression syndrome requiring surgery in 3 adolescent patients. J Pediatr Surg 2007;42:709-13.

9. Daniels AH, Jurgensmeier D, McKee J, Harrison MW, d'Amato CR. Acute celiac artery compression syndrome after surgical correction of Scheuermann kyphosis. Spine 2009;34:E149-52.

10. Geelkerken RH, van Bockel JH, de Roos WK, Hermans J. Coeliac artery compression syndrome: The effect of decompression. Br J Surg 1990;77:807-9. 


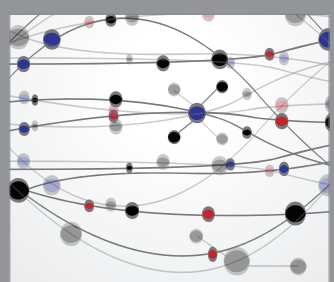

The Scientific World Journal
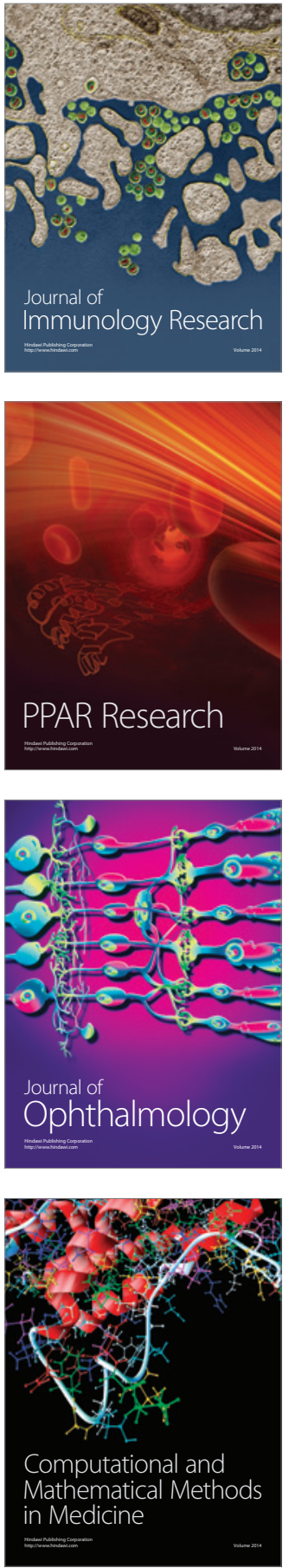

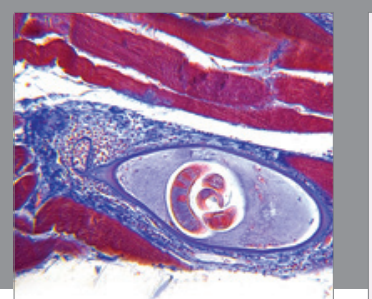

Gastroenterology Research and Practice

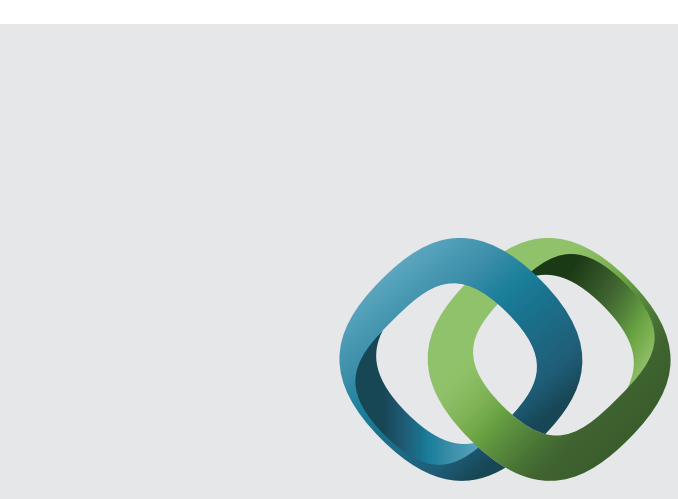

\section{Hindawi}

Submit your manuscripts at

http://www.hindawi.com
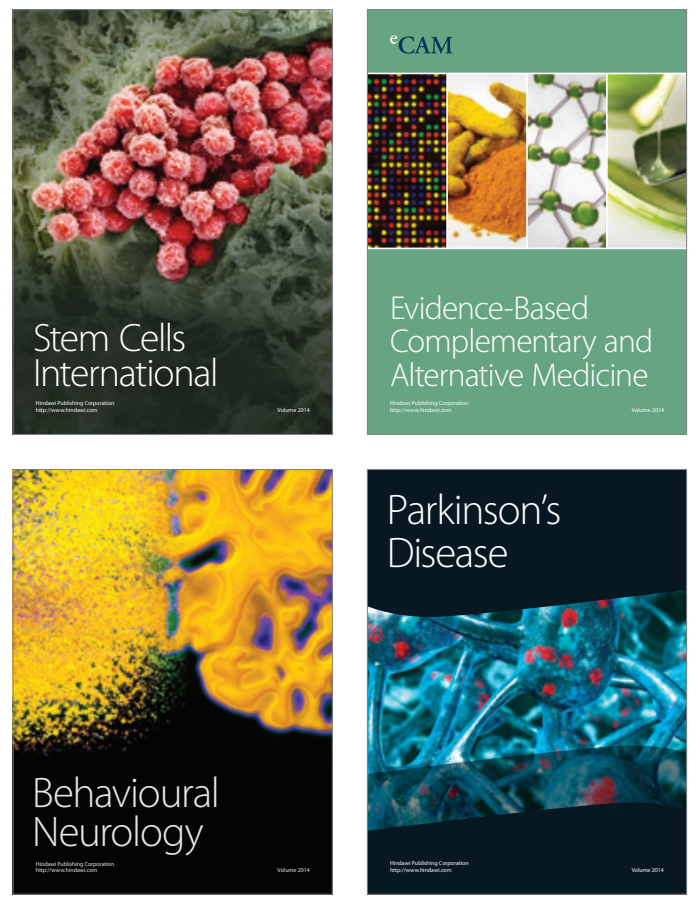
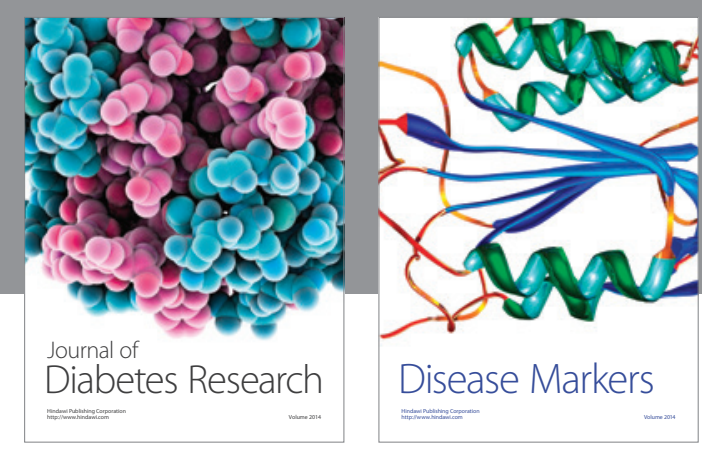

Disease Markers
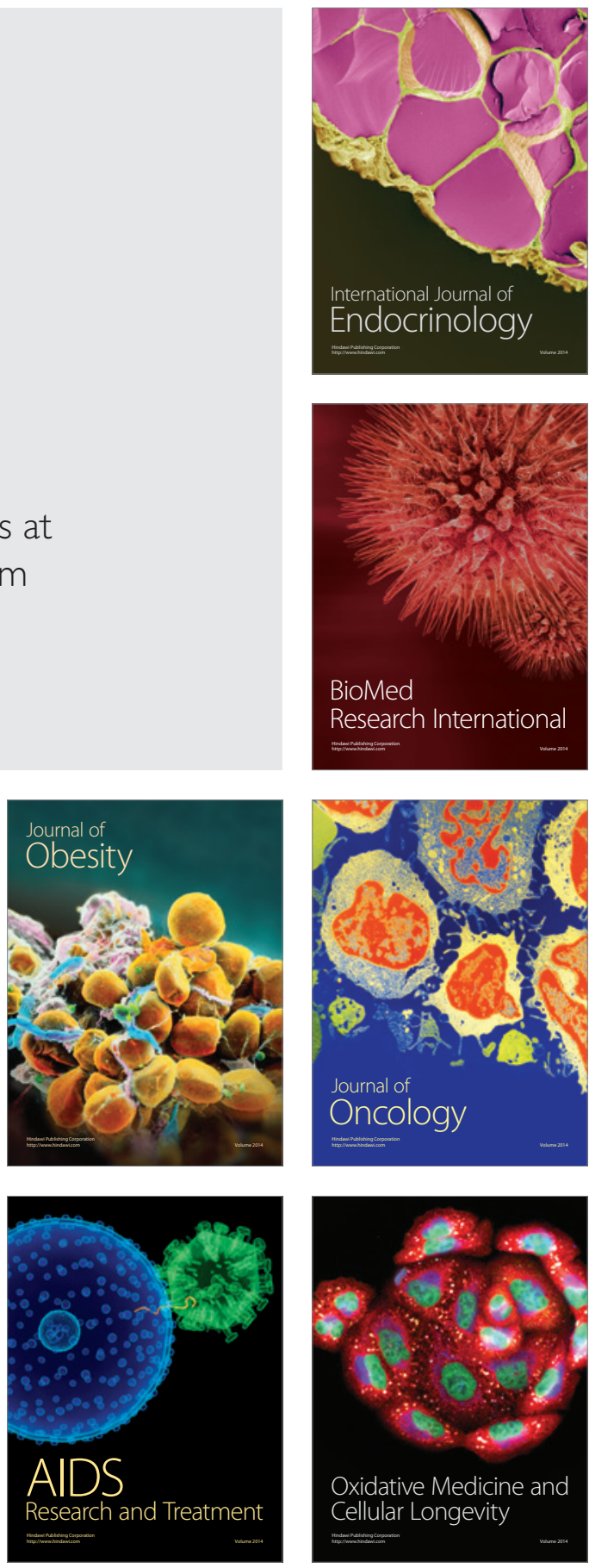